\title{
The Effect of Glycation on Epidermal Lipid Content, Its Metabolism and Change in Barrier Function
}

\author{
Mami Yokota Yoshihiro Tokudome \\ Laboratory of Dermatological Physiology, Faculty of Pharmaceutical Sciences, Josai University, Sakado, Japan
}

\section{Key Words}

Advanced glycation end products · Epidermal lipids · Fatty acid $\cdot$ Barrier function

\begin{abstract}
Background/Aims: Advanced glycation end products, which are linked to both aging and hyperglycemia, cause marked functional and structural alterations in human skin. Though it is well known that the metabolism of glucose is closely associated with that of fatty acid (FA), sharing the same energy-yielding reaction pathways as glucose, its effect on the epidermis has been unclear so far. Methods: Content of ceramides, cholesterol and FA in a reconstructed epidermal model glycated by glyoxal was analyzed by high-performance thin-layer chromatography. FA species extracted from $\mathrm{HaCaT}$ keratinocytes was determined by gas chromatography/mass spectrometry. Regulation of FA synthesis was analyzed by real-time PCR. For physiological analysis, excised mouse skin was glycated using a vertical diffusion cell and used for the evaluation of barrier function by transepidermal water loss measurement and observation of penetration of sodium fluorescein. Results: Saturated FA content was significantly increased in glycated epidermis, and
\end{abstract}

glycation upregulated mRNA expression of FA elongases 2 and 3 and FA synthase in $\mathrm{HaCaT}$ cells. Further, both insideout and outside-in barriers were disrupted in glycated excised skin. Conclusion: Biological and physical change in the epidermis, especially upregulation of FA synthesis by glycation, contributed to barrier disruption, and inhibiting glycation may offer an effective treatment option for aged or glycated skin.

(c) 2016 S. Karger AG, Basel

\section{Introduction}

Advanced glycation end products (AGEs), which are linked to both aging and hyperglycemia, cause marked functional and structural alterations in human skin $[1,2]$. AGEs are generated via the nonenzymatic Maillard reaction between the aldehyde group of reducing sugars and the amino group of proteins, lipids or nucleic acids $[3,4]$ (fig. 1). Skin accumulation of AGEs has been detected in both the epidermis and dermis $[2,5]$. In the epidermis, glycated keratin leads to a yellowish change in skin color and a decrease in water content of the stratum corneum (SC), resulting in skin dryness [6]. Moreover, glycation of

Yoshihiro Tokudome

Faculty of Pharmaceutical Sciences, Josai University

1-1 Keyakidai, Sakado, Saitama 350-0295 (Japan)

E-Mail tokudome@ josai.ac.jp 


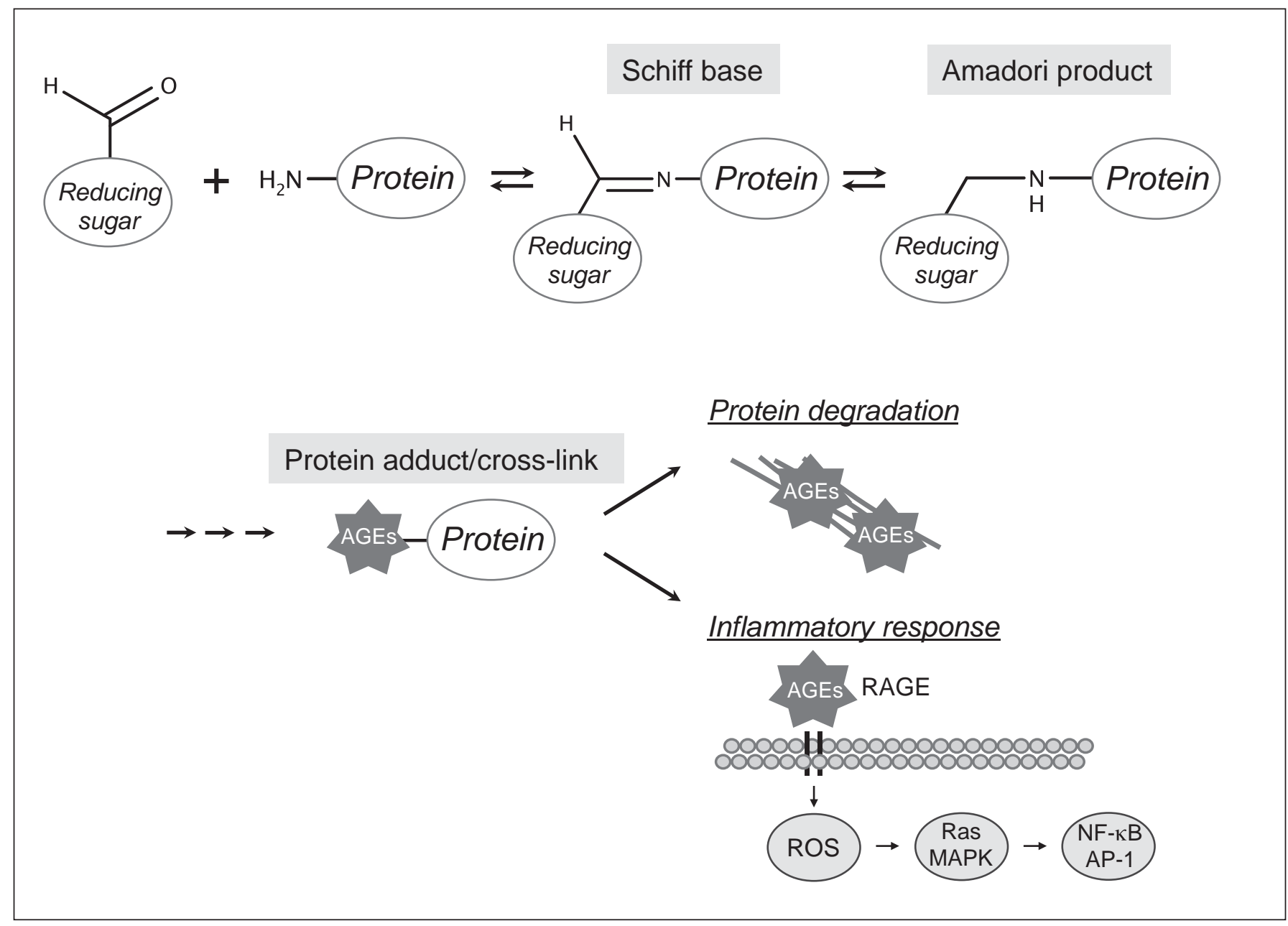

Fig. 1. Schematic presentation of AGE formation and their features. Aldehyde groups of reducing sugar react with amino groups of proteins to form Schiff base and more stable Amadori products. The resulting AGEs cause protein degradation as well as inflammatory response.

dermal collagen and elastic fibers contributes to stiffness and loss of elasticity, forming wrinkles [7, 8]. In addition to the modification of structural proteins, AGEs also induce biological reactions via binding to receptor for AGEs (RAGE) [9]. Binding of AGEs to RAGE induces activation of nuclear factor $\kappa \mathrm{B}$ and subsequent transcription of proinflammatory genes including interleukin 1 , tumor necrosis factor $\alpha$, matrix metalloproteinases and RAGE itself, accelerating further skin aging and deconstruction $[10,11]$.

It is well known that the metabolism of glucose is closely associated with that of fatty acid (FA) via accumulation of acetyl-CoA, sharing the same energy-yielding reaction pathways, and excess lipid accumulation in nonadipose tissue is associated with cytotoxicity $[12,13]$. FA is also a simple lipid included in phospholipids, triacylglycerol or ceramides and ubiquitously exists in cells as essential constituent of the cell membrane and is an important substrate for energy metabolism. So FA is produced by degradation of these complex lipids or newly synthesized from acetyl-CoA/malonyl-CoA to palmitic acid by FA synthase (FASN). The FA elongase (ELOVL) family protein is the most characterized enzyme for FA elongation to generate very-long-chain FAs [14]. Interestingly, there are strikingly unique lipid components in the SC, consisting of FA, ceramides, and cholesterol in an approximately equimolar ratio. They have an essential role in skin barrier function and are produced at the viable epidermis. 
Despite a strong relationship between glucose and FA metabolism, the effects of glycation on skin FA and barrier function have not been well studied so far. Thus, we focused on investigating the relationship between glycation and intercellular lipids and its effect on skin barrier function.

In this study, we elucidated that FA content was increased via upregulation of FASN and ELOVL expression in the glycation of epidermal keratinocytes, and change in the ratio of epidermal lipid component as well as structural alteration resulted in barrier disruption in the skin.

\section{Materials and Methods}

\section{Reagents}

Glyoxal, cholesterol and palmitic acid were purchased from Wako Pure Chemical Industries Ltd. (Osaka, Japan). Antibody specific for AGEs (6D12) was purchased from TransGenic Inc. (Tenjin, Fukuoka, Japan). Alexa 546-conjugated secondary antibody was purchased from Life Technologies (Carlsbad, Calif., USA). Thiazolyl blue tetrazolium bromide was purchased from Sigma-Aldrich (St. Louis, Mo., USA). For lipid standards, ceramides NS and AS were purchased from Matreya (State College, Pa., USA), and ceramides NP and NH were purchased from Evonic Industries AG (Essen, Germany). Gas chromatography/mass spectrometry (GC-MS) standard (FAME Mix RM-3) was purchased from Supelco (Bellefonte, Pa., USA).

\section{Cell Culture}

Immortalized human skin keratinocyte cell line HaCaT keratinocytes were maintained in Dulbecco's modified Eagle's medium supplemented with $10 \%$ fetal bovine serum and incubated in a humidified atmosphere of $5 \% \mathrm{CO}_{2}$ at $37^{\circ} \mathrm{C}$. AGEs were induced by glyoxal. After $30 \mathrm{~min}$ of exposure to glyoxal in culture medium, cells were washed twice, and the solution was replaced with fresh culture medium.

A reconstructed epidermal model (Labcyte Epimodel) was purchased from JTEC (Gamagori, Aichi, Japan) and maintained in supplied culture medium. AGEs were induced by exposing various concentrations of glyoxal for $72 \mathrm{~h}$ from the basal side.

\section{Cell Viability Assay}

$\mathrm{HaCaT}$ keratinocytes were cultured for $24 \mathrm{~h}$ before exposure to diverse concentrations of glyoxal. After $48 \mathrm{~h}$ of incubation, cells were washed and incubated with $0.5 \mathrm{mg} / \mathrm{ml}$ thiazolyl blue tetrazolium bromide in culture medium for a further $4 \mathrm{~h}$. The resulting formazan crystal was solubilized in $0.04 \mathrm{M}$ hydrochloric acid/isopropyl alcohol. The absorbance at $570 \mathrm{~nm}$ was measured using a microplate reader (SpectraMax M2 ${ }^{\mathrm{e}}$, Molecular Devices, Sunnyvale, Calif., USA).

\section{RNA Extraction and Quantitative Real-Time PCR}

Total RNA was isolated from HaCaT cells using RNAiso Plus (Takara Bio, Otsu, Japan), followed by reverse transcription to cDNA using a PrimeScript ${ }^{\circledR}$ RT reagent kit (Takara Bio) on a thermal cycler (Veriti, Applied Biosystems, Foster City, Calif., USA).
Real-time PCR reaction was performed using SYBR ${ }^{\circledR}$ Premix Ex Taq $^{\mathrm{TM}}$ (Takara Bio) on StepOnePlus ${ }^{\mathrm{TM}}$ (Applied Biosystems) with respective primers (suppl. table 1; for all online suppl. material, see www.karger.com/doi/10.1159/000448121). The n-fold change of expression was calculated according to the $\Delta \Delta \mathrm{C}_{\mathrm{T}}$ method using glyceraldehyde-3-phosphate dehydrogenase as endogenous control.

\section{Immunocytochemistry}

HaCaT cells were cultured on glass slides (Fisher brand, Fisher Scientific UK Ltd., Loughborough, UK) with subsequently induced glycation. After $48 \mathrm{~h}$ of incubation, cells were washed twice with PBS and fixed with ice-cold methanol for $15 \mathrm{~min}$ at $-30^{\circ} \mathrm{C}$. Nonspecific staining was blocked by preincubation with $1 \%$ bovine serum albumin in PBS for $1 \mathrm{~h}$ at room temperature. For the primary antibody reaction, cells were incubated with the antibody against AGEs at a 1:200 dilution in Can Get Signal immunostain ${ }^{\circledR}$ solution A (Toyobo, Osaka, Japan) overnight at $4^{\circ} \mathrm{C}$. Bound antibodies were visualized with Alexa 546-conjugated secondary antibody at a 1:200 dilution in Can Get Signal immunostain ${ }^{\circledR}$ solution A for $1 \mathrm{~h}$ at room temperature. After washing, hoechst33258 (Dojindo Laboratories, Mashiki, Japan) was added for nuclear counterstaining. All images were obtained using an IX71 microscope (Olympus, Tokyo, Japan).

\section{Lipid Extraction}

For lipid extraction from $\mathrm{HaCaT}$ cells, $4 \times 10^{5}$ cells were plated on a $6-\mathrm{cm}$ plate. Then, $48 \mathrm{~h}$ after exposure to glyoxal, lipids were extracted according to the method of Bligh and Dyer [15] with slight modifications. Briefly, cells were washed and scraped from dishes to $1.2 \mathrm{ml}$ of deuterium-depleted water. To lyse cells completely, the cell suspension was sonicated, and an aliquot of suspension was used to determine protein quantity by the conventional Lowry method. $3 \mathrm{ml}$ of $\mathrm{CHCl}_{3}$ and $\mathrm{MeOH}$ was added to the cell suspension before further sonication. Then samples were filtrated and $1.5 \mathrm{ml}$ of deuterium-depleted water was added, followed by centrifugation at $215 \mathrm{~g}$ for $20 \mathrm{~min}$. Lower layers were collected and dried under an $\mathrm{N}_{2}$ stream and used as lipid samples.

Epidermal lipid samples from reconstructed epidermal models were extracted in $\mathrm{CHCl}_{3} / \mathrm{MeOH}$ 2:1 (v/v) solution after having been washed and excised from Transwell supports. Minced and sonicated for $10 \mathrm{~min}$, the solution was filtrated, then dried under an $\mathrm{N}_{2}$ stream. All lipid extracts and standards were dissolved in $\mathrm{CHCl}_{3} / \mathrm{MeOH}$ 2:1 (v/v) solution.

\section{High-Performance Thin-Layer Chromatography Analysis}

$10 \mu \mathrm{l}$ of lipid extracts were applied on the high-performance thin-layer chromatography (HPTLC) plate (HPTLC Silica gel 60 , Merck KGaA, Darmstadt, Germany) together with lipid standards to generate calibration curves and developed twice in a saturated chromatographic chamber containing a $\mathrm{CHCl}_{3} / \mathrm{MeOH} /$ $\mathrm{CH}_{3} \mathrm{COOH}$ 190:9:1 (v/v/v) mobile phase. Then, the HPTLC plate was dried and sprayed with a reagent $\left(10 \% \mathrm{CuSO}_{3}, 8 \% \mathrm{H}_{3} \mathrm{PO}_{4}\right.$ aqueous solution) and heated at $180^{\circ} \mathrm{C}$ for $10 \mathrm{~min}$ and quantitated by densitometry using Image $\mathrm{J}$.

\section{GC-MS Analysis}

FA species were analyzed as described previously, with slight modification $[16,17]$. The free FA fraction was isolated from total lipids by HPTLC, followed by methyl esterification using odd- 


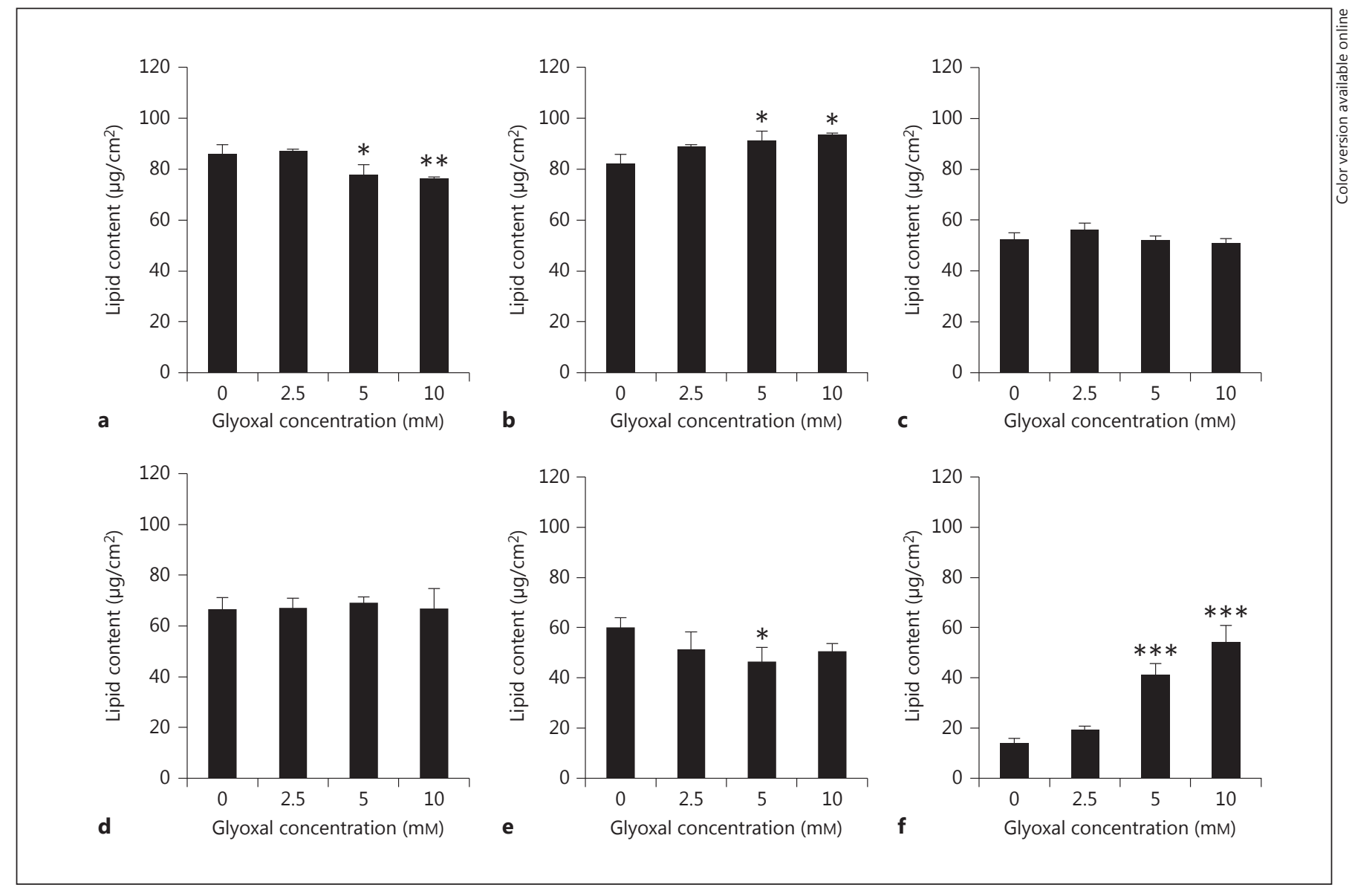

Fig. 2. Changes in the content of epidermal lipids in reconstructed epidermal model after 96-hour exposure to glyoxal determined by HPTLC: ceramide NS (a), ceramide NP (b), ceramide AS (c), ceramide $\mathrm{NH}(\mathbf{d})$, cholesterol (e), FA (f), and total lipid (g). All results are expressed as the mean \pm SD of $\mathrm{n}=3$ replicates. ${ }^{*} \mathrm{p}<0.05$, ** $\mathrm{p}<0.01,{ }^{* * *} \mathrm{p}<0.001$.

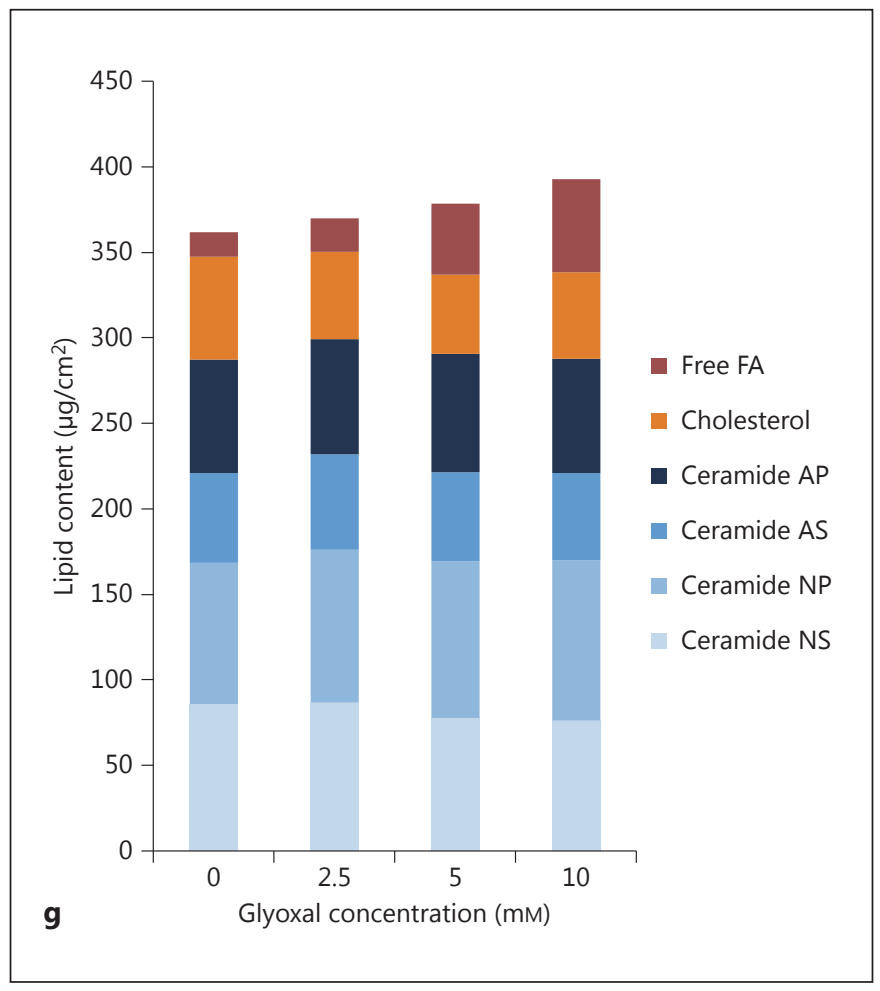


Fig. 3. TEWL of reconstructed epidermal model after exposure to glyoxal: $0 \mathrm{~h}(\mathbf{a})$, $24 \mathrm{~h}$ (b), $48 \mathrm{~h} \mathrm{(c),} \mathrm{and} 72 \mathrm{~h}(\mathbf{d})$. All results are expressed as the mean \pm SD of $n=3$ replicates. ${ }^{* * *} \mathrm{p}<0.001$.
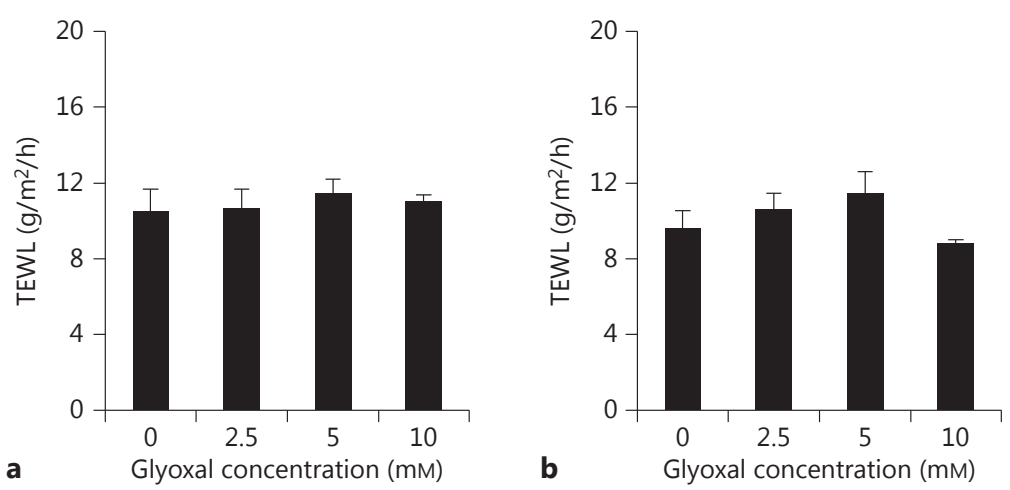

b

Glyoxal concentration (mM)

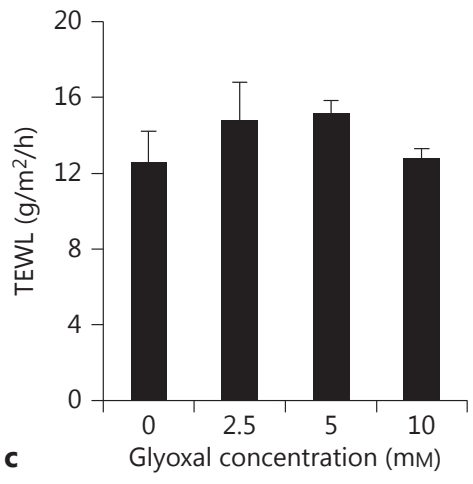

numbered FA as internal standard. Then derivatives were analyzed by GC (HP6890 series GC system; Hewlett Packard) and MS (JMS700; JEOL, Japan) on a Restek RTX-5 column (30 m × 0.25 $\mathrm{mm}$ i.d., $0.25 \mu \mathrm{m}$ d.f., Restek Corporation, Bellefonte, Pa., USA). The initial temperature was $110^{\circ} \mathrm{C}$ with $10^{\circ} \mathrm{C}$ increases each minute up to $300^{\circ} \mathrm{C}$.

\section{Animals}

Seven- to 10-week-old male hairless mice (Hos: HR-1) were purchased from Hoshino Experiment Animal Center (Bando, Japan). All animal experiments were carried out in accordance with the guidelines of, and approved by, the Animal Research Committee of Josai University.

\section{Induction of Glycation and Penetration Experiments}

Skin samples removed from mice and cleaned of subcutaneous tissue and fat were mounted on vertical diffusion cells. The cells used in this study had an effective diffusion area of $1.77 \mathrm{~cm}^{2}$ and a receptor compartment volume of $5.0 \mathrm{ml}$. For induction of glycation, the skin specimens were hydrated with PBS (control) or PBS containing $50 \mathrm{~mm}$ glyoxal for $24 \mathrm{~h}$. Glycation was induced from the basal side. The receptor fluid was maintained at $32^{\circ} \mathrm{C}$ and continuously agitated with a magnetic stirrer bar.

For imaging of FL-Na penetration, skin specimens were removed from the diffusion cells 0,1 , and $6 \mathrm{~h}$ after application of $1 \mathrm{mM}$ of FL-Na, the SC surface was washed 7 times with purified water. Skin specimens were embedded in OCT compound (Sakura
Finetek Japan Co. Ltd., Tokyo, Japan), snap-frozen in liquid nitrogen, and frozen samples were cut into $20-\mu \mathrm{m}$-thick sections. All images were obtained using an IX71 microscope (Olympus, Tokyo, Japan). Intensity was obtained by an Image J Histogram tool.

\section{Measurement of Transepidermal Water Loss}

Cutaneous water evaporation was measured with a Vaposcan AS-VT100RS (Asahibiomed, Yokohama, Japan). For measurement of excised skin, the skin surface temperature was kept at $37^{\circ} \mathrm{C}$ on the diffusion cells to obtain a stable transepidermal water loss (TEWL) value. Reconstructed epidermal models were naturalized $1 \mathrm{~h}$ before measurement and measured using the attachment fitted to a Labcyte Epimodel well.

\section{Measurement of Skin Color}

Skin color was measured using a chromameter CR-400 (Konica-Minolta, Tokyo, Japan). The measurement of skin samples was performed by placing the skin samples on a white board. Data are expressed in the $\mathrm{L}^{*} \mathrm{a}^{*} \mathrm{~b}^{*}$ color space, and the parameter $\mathrm{b}^{*}$ was employed as the value for yellowish tint.

\section{Data Analysis}

Statistical differences between groups were assessed by means of Dunnett's test or the 2-tailed Student t test using the SAS statistics software (SAS Institute, Cary, N.C., USA), and a p value of $<0.05$ was considered as the limit of statistical significance. A test of correlation coefficients was conducted using Microsoft Excel 2011. 


\section{Results}

The Component Ratio of Lipids Is Changed in the Glycated Reconstructed Epidermal Model

We first evaluated the component ratio of SC intercellular lipids in glycated epidermis. Thus, we used a reconstructed epidermal model and determined the quantity of free FA, ceramides, and cholesterol. The content of FA in normal and $10 \mathrm{~mm}$ glyoxal-exposed reconstructed epidermal model was 14.0 and $54.4 \mathrm{mg} / \mathrm{cm}^{2}$, respectively, inducing a 3.9 times higher free FA content in glycated epidermis (fig. $2 \mathrm{f}, \mathrm{p}<0.001$ ). Concentration dependency was not observed in the content of various ceramides or cholesterol (fig. 2a-e); thus, the component ratio of intercellular lipids was changed as shown in figure $2 \mathrm{~g}$. The TEWL value increased significantly $(\mathrm{p}<0.001)$ after $72 \mathrm{~h}$ exposure to glyoxal (fig. 3).

\section{Glyoxal-Induced Glycation Affects Viability of $\mathrm{HaCaT}$ Cells}

To evaluate the effect of glycation on skin at an early stage, we used $\mathrm{HaCaT}$ keratinocytes. The viability of $\mathrm{HaCaT}$ cells $48 \mathrm{~h}$ after exposure to $1.25 \mathrm{~mm}$ glyoxal for 30 min was $86.2 \%$ (fig. $4 \mathrm{a}, \mathrm{p}<0.001$ ) and decreased in a glyoxal concentration-dependent manner. Immunocytochemistry indicated that fluorescence intensity derived from AGEs was significantly increased by exposure to $5 \mathrm{mM}$ glyoxal. This result showed that 30-min exposure to $5 \mathrm{~mm}$ glyoxal was enough to induce glycation to cells $48 \mathrm{~h}$ after exposure (fig. $4 \mathrm{~b}, \mathrm{c}$ ).

\section{Glycated HaCaT Cells Accelerate Free FA Production}

We next measured the content of various lengths of FA in glycated $\mathrm{HaCaT}$ cells. Amounts of C14:0, C16:0, C18: 0 , and C20:0 contained in the lipid extract from glycated $\mathrm{HaCaT}$ cells were $0.28,12.7,10.0$, and $0.08 \mu \mathrm{g} / \mu \mathrm{g}$ protein, though those from normal HaCaT cells were 0.46, 27.9, 21.1 , and $0.12 \mu \mathrm{g} / \mu \mathrm{g}(\mathrm{p}<0.05, \mathrm{p}=0.07, \mathrm{p}<0.05, \mathrm{p}<0.05$; fig. $4 \mathrm{~d})$. These results indicated that production of saturated FAs was accelerated by cellular glycation.

\section{Increase in FASN and ELOVL mRNA Expression}

\section{Induces Glycation-Induced Free FA Accumulation}

To address whether the increase in free FA derived from de novo synthesis, we examined FASN and ELOVL mRNA expression in glycated HaCaT cells. FASN contributes to production of $\mathrm{C} 16$ and ELOVL contributes to that of C16<. In known ELOVL families, ELOVL2 and ELOVL3 were 18.3 and 8.9 times upregulated in glycated $\mathrm{HaCaT}$ cells $6 \mathrm{~h}$ after exposure to glyoxal, respectively

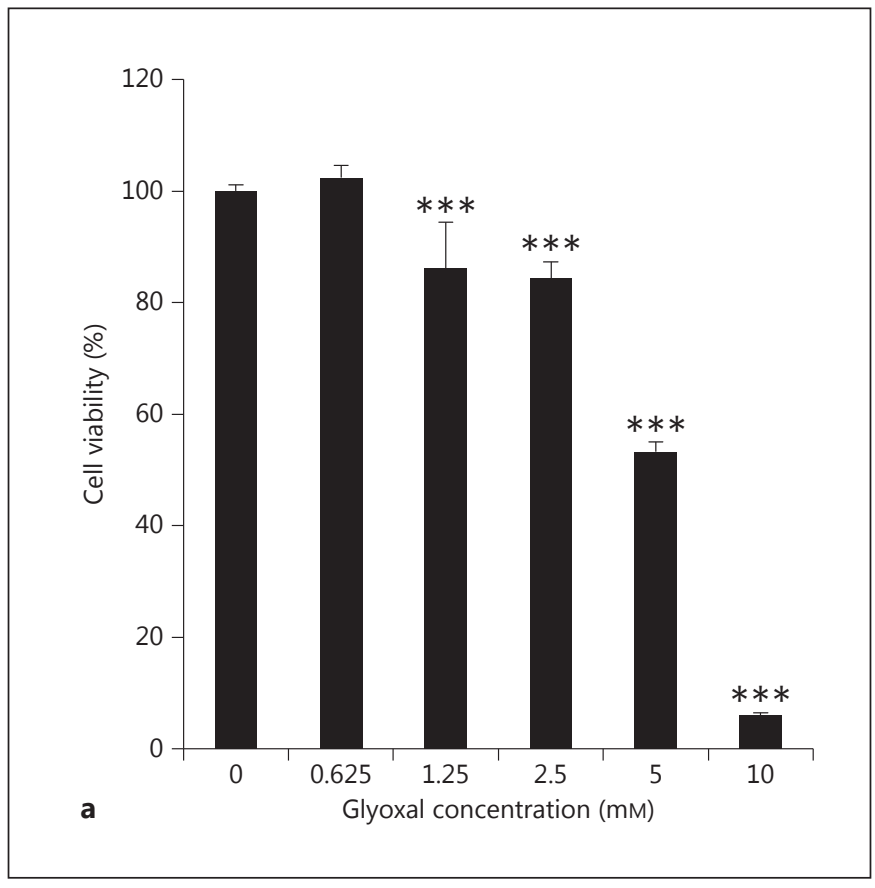

Fig. 4. a Viability of HaCaT cells $48 \mathrm{~h}$ after 30-min exposure to glyoxal determined by the thiazolyl blue tetrazolium bromide assay. ${ }^{* * *} \mathrm{p}<0.001$.

(fig. 5a-g; $\mathrm{p}<0.001$ for both). FASN expression was 2.7 times increased after $48 \mathrm{~h}$ glyoxal treatment (fig. $5 \mathrm{~h}, \mathrm{p}<$ 0.05).

\section{Excised Glycated Skin Model Increases Inside-Out and} Outside-In Barrier Function

The physiological barrier integrity of the skin was assessed using excised glycated skin for the evaluation of biological and physical change in SC. An excised glycated skin model showed a yellowish tint and an increase in autofluorescence in a glyoxal concentration-dependent manner (fig. 6a). TEWL levels of each sample were measured under hydrated conditions at $37^{\circ} \mathrm{C}$. A correlation of TEWL levels and the $b^{*}$ value in glycated skin was observed as shown in figure $6 \mathrm{~b}$ but was not significant with $\mathrm{r}=0.47(\mathrm{p}=0.07)$.

To determine the partition distance from the SC in normal and glycated skin, we investigated the skin penetration of FL-Na (MW: 376.28 Da; fig. 7). One hour after application, FL-Na was distributed to the SC and observed in all layers of the skin in excised glycated skin, although there was only a slight distribution to the SC in normal skin. After $6 \mathrm{~h}$, the distribution of FL-Na to the $\mathrm{SC}$ was increased in both groups. However, excised gly- 

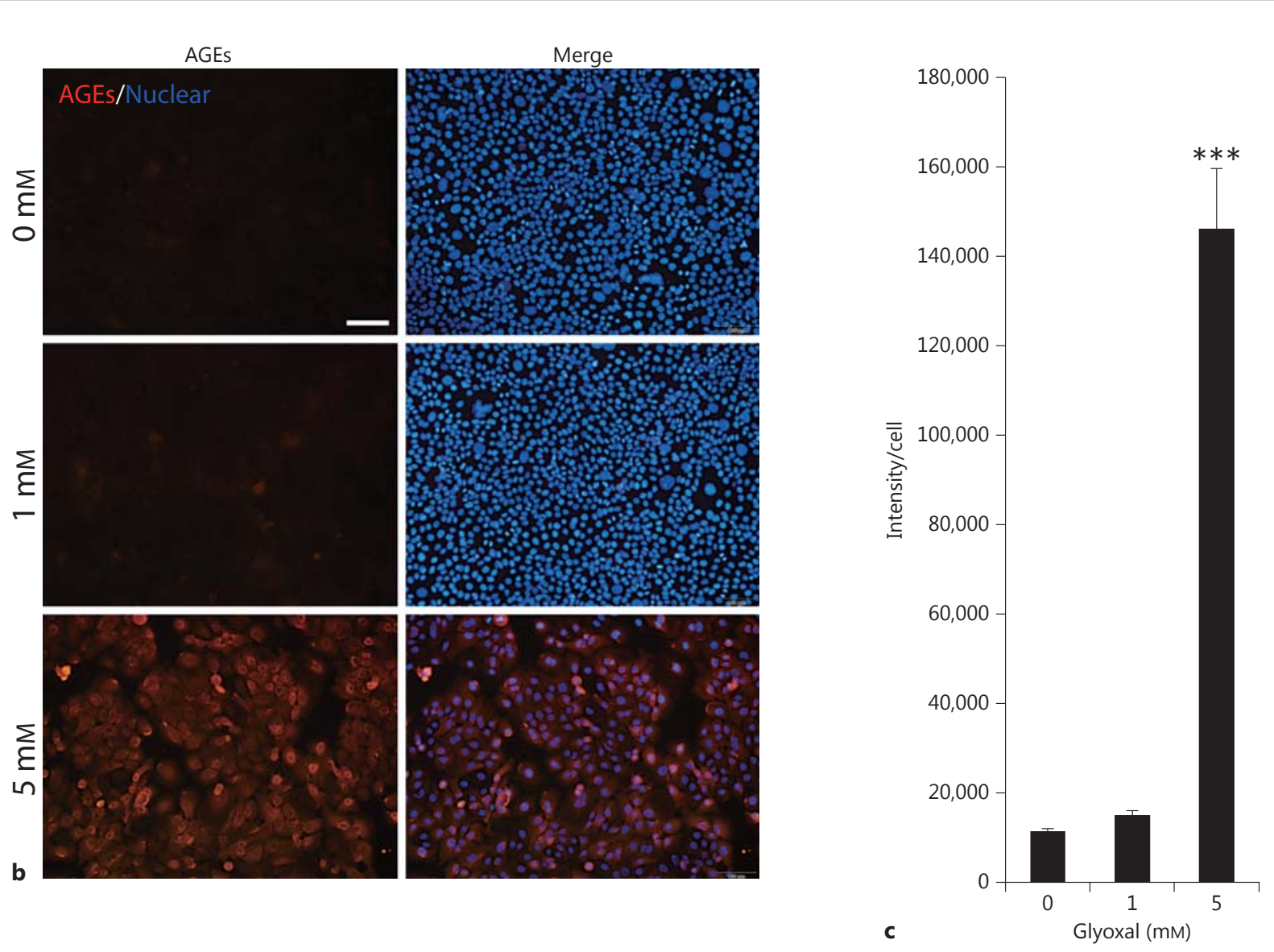

Fig. 4. b Immunohistochemical analysis for AGEs in the same conditions as in figure $4 \mathrm{a}$. c The intensity derived from AGEs was divided by the cell number, calculated using Image J. d The content of various lengths of FA was determined by GC-MS. Lipids were extracted from $\mathrm{HaCaT}$ cells exposed to $0 \mathrm{mM}$ (control) or $5 \mathrm{mM}$ (AGEd) of glyoxal for $30 \mathrm{~min}$ followed by 48 -hour incubation. Cell viability is expressed as the mean \pm SD of $n=4$ replicates. The others are expressed as the mean $\pm \mathrm{SD}$ of $\mathrm{n}=3$ replicates. ${ }^{*} \mathrm{p}<0.05$.

Relationship between AGEs and Epidermal Lipid Metabolism

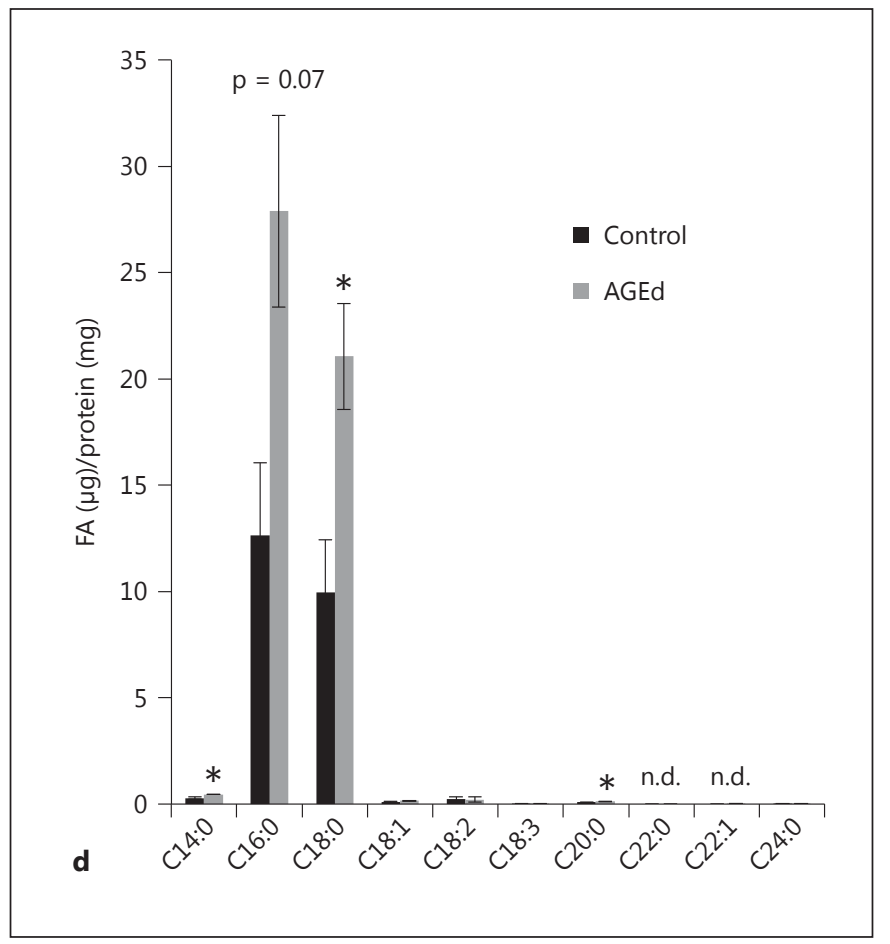

Skin Pharmacol Physiol 2016;29:231-242 


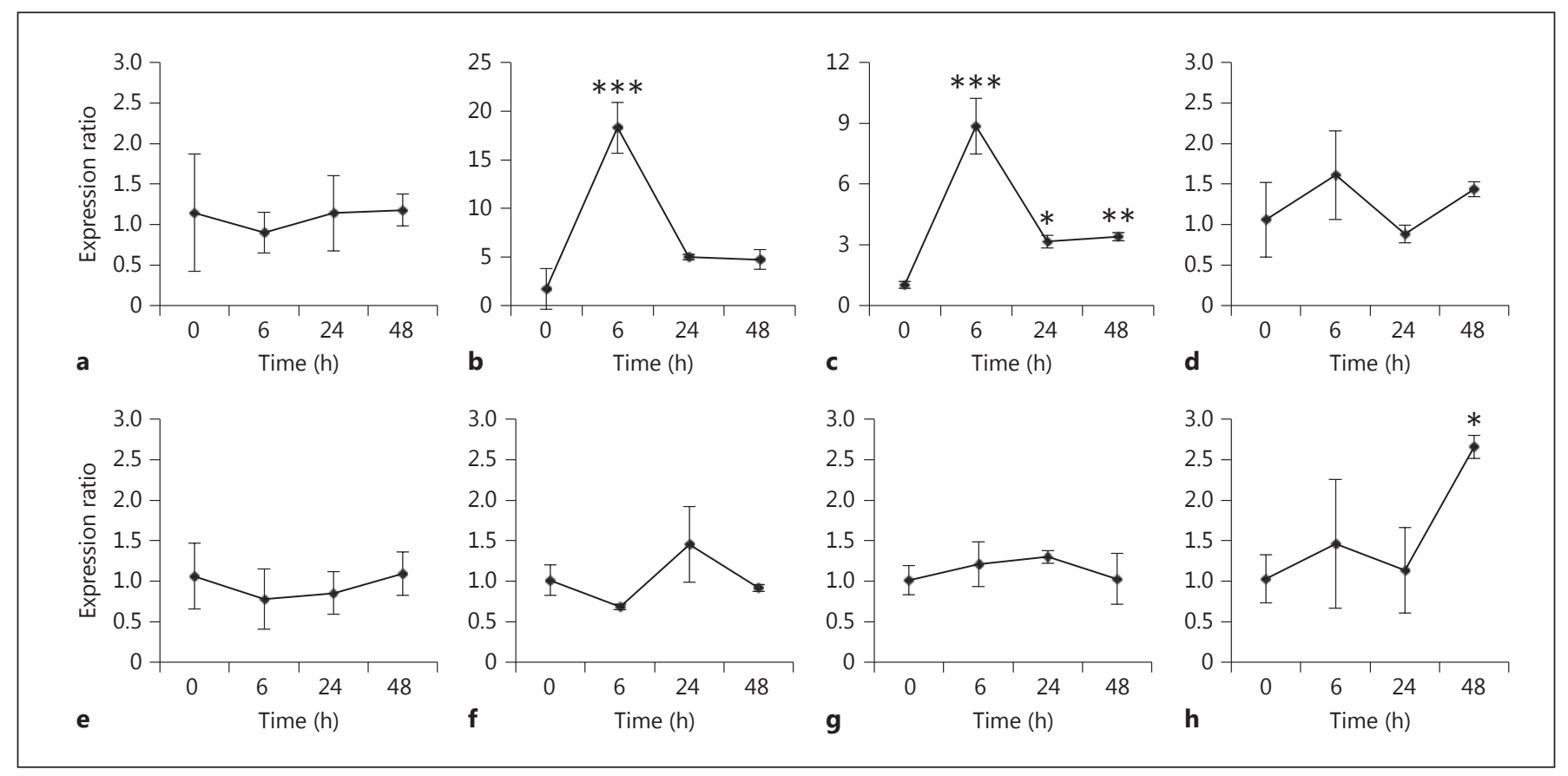

Fig. 5. Changes in expression of FA synthesis-related genes determined by real-time PCR: ELOVL1-7 (a-g) and FASN (h). All results are expressed as the mean \pm SD of $\mathrm{n}=3$ replicates. ${ }^{*} \mathrm{p}<0.05,{ }^{* *} \mathrm{p}<0.01,{ }^{* * *} \mathrm{p}<0.001$

cated skin showed a higher intensity especially at the SC. These results suggested that only change in structure of the SC by glycation could cause a disrupted penetration of FL-Na across the skin.

\section{Discussion}

In the present study, we clarified the effect of glycation on epidermal lipid content, its metabolism and change in barrier function.

The most striking feature in the epidermal lipid profiles of glycated skin was the increase in various lengths of FA (fig. 2, 4), suggesting the involvement of new synthesis of FA, via FASN and ELOVL upregulation (fig. 5). FAs with a chain length up to $\mathrm{C} 16$ are synthesized by the FASN complex, and ELOVL family protein elongates them. Among 7 mammalian homologues (ELOVL1-7), ELOVL 3 and 4 are highly expressed in the skin $[14,18]$. Thus, upregulation of ELOVL3 in glycated cells explains the increase in various lengths of FA in $\mathrm{HaCaT}$ cells (fig. 4). In skin stratum granulosum, FA is said to be produced via phospholipase $\mathrm{A}_{2}$ from phospholipids to control skin pH [19]. In the present study, we used HaCaT cells, and they represent the stratum basale of the skin.
For this reason, treatment of bromophenacyl bromide, an inhibitor of phospholipase $\mathrm{A}_{2}$, did not affect the FA content in $\mathrm{HaCaT}$ cells in our experiment (data not shown). Taken together, the FA metabolism might be differentially regulated in differentiating keratinocytes and proliferating keratinocytes. Also, ceramidase or ceramide synthase activity could affect the FA content. For further understanding the contribution of phospholipase $\mathrm{A}_{2}$ or other enzymes in glycated skin, a reconstructed epidermal model will be useful for investigation.

One of the unsolved questions is the reason why FASN and ELOVL were upregulated in glycated skin (fig. 5). Exposure to excess glucose metabolites is known to contribute to the upregulation of lipid synthesis in many types of cells and primary regulators of lipid synthesis including liver X receptors, sterol regulatory element-binding protein-1c, and carbohydrate response element-binding protein transcription factors [20-22]. Though further investigation is needed to clarify the contribution of these pathways, these mechanisms may also be applicable for keratinocytes.

There are several mechanisms through which the TEWL value is affected (fig. 3, 6). One possible mechanism is change in physiological properties of SC intercellular lipids caused by the increasing FA ratio. The other 
Fig. 6. Inside-out and outside-in permeability across the excised glycated skin model. a Macroscopic view of excised hairless mouse skin after incubation with various concentrations of glyoxal. b TEWL of excised skin with various b* values prepared by exposure to various concentrations of glyoxal. c Penetration pattern of FL-Na across normal and glycated skin at indicated time points. d Vertical intensity derived from FL-Na at an arbitrary line calculated using Image J. Glycation was induced by hydration with $50 \mathrm{mM}$ of glyoxal in PBS at $32^{\circ} \mathrm{C}$ or $37^{\circ} \mathrm{C}$ (for TEWL measurement) for $24 \mathrm{~h}$.
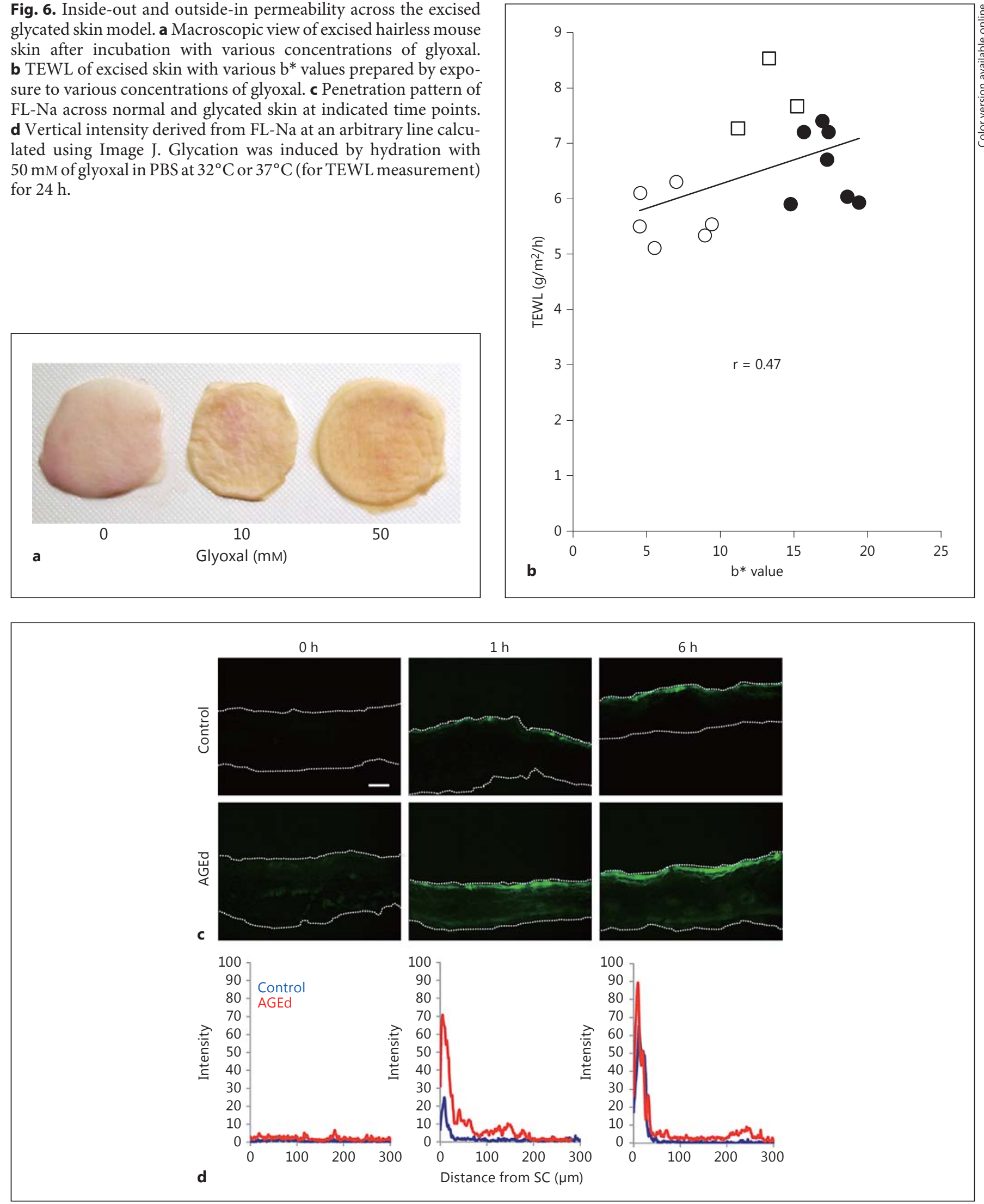

Relationship between AGEs and Epidermal Lipid Metabolism 


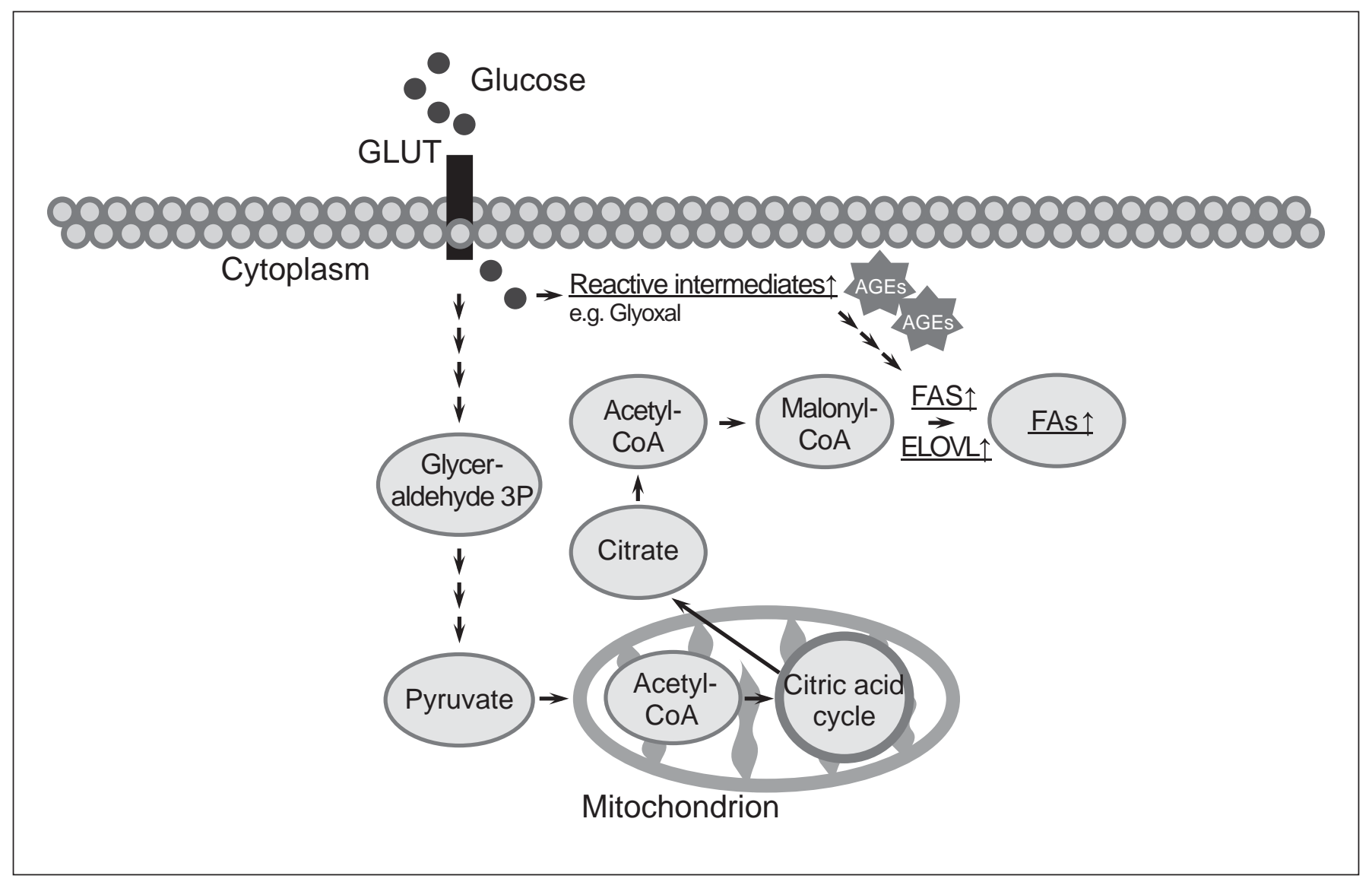

Fig. 7. Glucose and FA metabolism and predicted mechanism for upregulation of FA synthesis by glycation stress. Reactive intermediates (e.g. glyoxal) are produced from autoxidation of glucose, inducing formation of AGEs. The present study elucidated that excess glycation stress increased the production of FAs in the epidermis. This may be caused by mRNA expression of FAS and ELOVL2 and 3 (underlined). GLUT = Glucose transporter; $3 \mathrm{P}=3$-phosphate.

is cytotoxicity from saturated lipid, which is significantly increased in glycated $\mathrm{HaCaT}$ cells. FA-induced apoptosis is specific for the saturated FAs (C16:0 and C18:0) and does not occur with the C4-C14 saturated or unsaturated one [23, 24]. Listenberger et al. [12] reported that palmitate caused cell death not via ceramide synthesis but reactive oxygen species production in Chinese hamster ovary cells. Consistent with this, our data did not show any increase in ceramide content either, and a previous study in which active oxygen species were generated in the advanced glycation process supports the hypothesis that reactive oxygen species contribute to FA-induced apoptosis in the epidermis [25].

We investigated the effect of alterations in SC structure using excised skin and showed that both inside-out and outside-in barriers were disrupted by inducing glyca- tion (fig. 6). It is well documented that percutaneous penetration occurs through intracellular, transcellular, and, to a lesser extent, appendageal routes [26]. Notably, hydrophilic molecules diffuse across the polar head of the lipid as a major route. As hydrophilic compounds showed higher permeation in glycated skin, it is thought that modification of the polar head of intercellular lipids by AGEs derived from glyoxal causes barrier disruption, leading to an increase in penetration rate as documented in permeation across excised glycated skin [27]. In a future study, we need to improve the condition to induce glycation to cells. We used glyoxal as glycation inducer in the present study, which is widely used in in vitro studies $[28,29]$. Glyoxal is one of the glycation inducers produced by spontaneous degradation of glucose [30]. The plasma concentration of glyoxal in diabetes mellitus pa- 
tients is known to increase compared with healthy counterparts [31]. Thus, the results from glyoxal induction are thought to be predictive of in vivo human performances to a certain degree. However, the in vivo glycation is a complex process caused by various species of glycation inducer, over a period of several years. Improved experimental systems are required to mimic the human in vivo glycation and to understand in detail the effect of glycation on the skin.

Kim et al. [32] reported that the composition of FAs is changed in aged skin and the synthesis of FAs is decreased in UV-irradiated skin [33], which are opposite outcomes compared to ours, suggesting that there may be specific pathways for glycation-induced upregulation of the FA metabolism.

In conclusion, biological and physical change in the epidermis, especially upregulation of FA synthesis by gly- cation, contributed to barrier disruption, and inhibiting glycation may offer an effective treatment option for aged or glycated skin.

\section{Statement of Ethics}

All animal experiments were carried out in accordance with the guidelines of, and approved by, the Animal Research Committee of Josai University.

\section{Disclosure Statement}

There is no conflict of interest with any commercial or other associations in this study.

\section{References}

1 Crisan M, Taulescu M, Crisan D, Cosgarea R, Parvu A, Cãtoi C, Drugan T: Expression of advanced glycation end-products on sun-exposed and non-exposed cutaneous sites during the ageing process in humans. PLoS One 2013;8:e75003.

2 Schleicher ED, Wagner E, Nerlich AG: Increased accumulation of the glycoxidation product $\mathrm{N} \varepsilon$-(carboxymethyl)lysine in human tissues in diabetes and aging. J Clin Invest 1997;99:457-468.

3 Gkogkolou, Böhm M: Advanced glycation end products: key players in skin aging? Dermatoendocrinology 2012;4:259-270.

4 Ichihashi M, Yagi M, Nomoto K, Yonei Y: Glycation stress and photo-aging in skin. Antiaging Med 2011;8:23-29.

5 Kawabata K, Yoshikawa H, Saruwatari K, Akazawa $Y$, Inoue T, Kuze T, Sayo T, Uchida $\mathrm{N}$, Sugiyama Y: The presence of $\mathrm{N}(\varepsilon)$-(carboxymethyl)lysine in the human epidermis. Biochim Biophys Acta 2011;1814:1246-1252.

6 Sakai S, Kikuchi K, Satoh J, Tagami H, Inoue S: Functional properties of the stratum corneum in patients with diabetes mellitus: similarities to senile xerosis: Br J Dermatol 2005; 153:319-323.

7 Verzijl N, DeGroot J, Thorpe SR, Bank RA, Shaw JN, Lyons TJ, Bijlsma JW, Lafeber FP, Baynes JW, TeKoppele JM: Effect of collagen turnover on the accumulation of advanced glycation end products. J Biol Chem 2000; 275:39027-39031.
8 Yoshinaga E, Kawada A, Ono K, Fujimoto E, Wachi H, Harumiya S, Nagai R, Tajima S: NE(carboxymethyl)lysine modification of elastin alters its biological properties: implications for the accumulation of abnormal elastic fibers in actinic elastosis. J Invest Dermatol 2012;132:315-323.

9 Lohwasser C, Neureiter D, Weigle B, Kirchner T, Schuppan D: The receptor for advanced glycation end products is highly expressed in the skin and upregulated by advanced glycation end products and tumor necrosis factor-alpha. J Invest Dermatol 2006; 126:291-299.

10 Leibold JS, Riehl A, Hettinger J, Durben M, Hess J, Angel P: Keratinocyte-specific deletion of the receptor RAGE modulates the kinetics of skin inflammation in vivo. J Invest Dermatol 2013;133:2400-2406.

11 Zhu P, Ren M, Yang C, Hu YX, Ran JM, Yan $\mathrm{L}$ : Involvement of RAGE, MAPK and NF- $\mathrm{kB}$ pathways in AGE-induced MMP-9 activation in HaCaT keratinocytes. Exp Dermatol 2012; 21:123-129.

12 Listenberger LL, Ory DS, Schaffer JE: Palmitate-induced apoptosis can occur through a ceramide-independent pathway. J Biol Chem 2001;276:14890-14895.

13 Arner P: Insulin resistance in type 2 diabetes: role of fatty acids. Diabetes Metab Res Rev 2002;18(suppl 2):S5-S9.

14 Uchida Y: The role of fatty acid elongation in epidermal structure and function. Dermatoendocrinology 2011;3:65-69.

15 Bligh EG, Dyer WJ: A rapid method of total lipid extraction and purification. Can J Biochem Physiol 1959;37:911-917.
16 Hamanaka S, Hara M, Nishio H, Otsuka F, Suzuki A, Uchida Y: Human epidermal glucosylceramides are major precursors of stratum corneum ceramides. J Invest Dermatol 2002; 119:416-423.

17 Uchida Y, Hama H, Alderson NL, Douangpanya S, Wang Y, Crumrine DA, Elias PM, Holleran WM: Fatty acid 2-hydroxylase, encoded by $\mathrm{FA} 2 \mathrm{H}$, accounts for differentiation-associated increase in 2-OH ceramides during keratinocyte differentiation. J Biol Chem 2007; 282:13211-13219.

18 Ohno Y, Nakamichi S, Ohkuni A, Kamiyama N, Naoe A, Tsujimura H, Yokose U, Sugiura K, Ishikawa J, Akiyama M, Kihara A: Essential role of the cytochrome P450 CYP4F22 in the production of acylceramide, the key lipid for skin permeability barrier formation. Proc Natl Acad Sci USA 2015;112:7707-7712.

19 Fluhr JW, Kao J, Jain M, Ahn SK, Feingold KR, Elias PM: Generation of free fatty acids from phospholipids regulates stratum corneum acidification and integrity. J Invest Dermatol 2001;117:44-51.

20 Wang Y, Botolin D, Xu J, Christian B, Mitchell E, Jayaprakasam B, Nair MG, Peters JM, Busik JV, Olson LK, Jump DB: Regulation of hepatic fatty acid elongase and desaturase expression in diabetes and obesity. J Lipid Res 2006; 47:2028-2041.

21 Listenberger LL, Schaffer JE: Mechanisms of lipoapoptosis: implications for human heart disease. Trends Cardiovasc Med 2002;12: 134-138.
Relationship between AGEs and Epidermal Lipid Metabolism
Skin Pharmacol Physiol 2016;29:231-242 DOI: $10.1159 / 000448121$ 
22 Strable MS, Ntambi JM: Genetic control of de novo lipogenesis: role in diet-induced obesity. Crit Rev Biochem Mol Biol 2010;45:199-214.

23 Paumen MB, Ishida Y, Muramatsu M, Yamamoto M, Honjo T: Inhibition of carnitine palmitoyltransferase I augments sphingolipid synthesis and palmitate-induced apoptosis. J Biol Chem 1997;272:3324-3329.

24 De Vries JE, Vork MM, Roemen TH, de Jong YF, Cleutjens JP, van der Vusse GJ, van Bilsen M: Saturated but not mono-unsaturated fatty acids induce apoptotic cell death in neonatal rat ventricular myocytes. J Lipid Res 1997;38: 1384-1394.

25 Lee C, Yim MB, Chock PB, Yim HS, Kang SO: Oxidation-reduction properties of methylglyoxal-modified protein in relation to free radical generation. J Biol Chem 1998;273:2527225278.
26 Barry BW: Mode of action of penetration enhancers in human skin. J Control Release 1987;6:85-97.

27 Yokota M, Tokudome Y: Permeation of hydrophilic molecules across glycated skin is differentially regulated by the stratum corneum and epidermis-dermis. Biol Pharm Bull 2015;38:1383-1388.

28 Ogura Y, Kuwahara T, Akiyama M, Tajima S, Hattori K, Okamoto K, Okawa S, Yamada Y, Tagami H, Takahashi M, Hirao T: Dermal carbonyl modification is related to the yellowish color change of photo-aged Japanese facial skin. J Dermatol Sci 2011;64:45-52.

29 Quan KK, Kusewitt DF, Hudson LG: Glyoxal leads to defective keratinocyte migration and down-regulation of Snai2 diabetes. J Dermatol Sci 2014;73:166-169.
30 Thornalley PJ, Langborg A, Minhas HS: Formation of glyoxal, methylglyoxal and 3-deoxyglucosone in the glycation of proteins by glucose. Biochem J 1999;344:109-116.

31 Kielhorn J, Pohlenz-Michel C, Schmidt S, Mangelsdorf I: Concise International Chemical Assessment Document 57. Geneva, World Health Organization, 2004.

32 Kim EJ, Kim MK, Jin XJ, Oh JH, Kim JE, Chung JH: Skin aging and photoaging alter fatty acids composition, including 11,14 , 17-eicosatrienoic acid, in the epidermis of human skin. J Korean Med Sci 2010;25:980-983.

33 Kim EJ, Jin XJ, Kim YK, Oh IK, Kim JE, Park $\mathrm{CH}$, Chung JH: UV decreases the synthesis of free fatty acids and triglycerides in the epidermis of human skin in vivo, contributing to development of skin photoaging. J Dermatol Sci 2010;57:19-26. 